\title{
Modeling the Main Determinants of Movie Sales: An Econometric Study of Chinese Marketplace
}

\author{
Fan Feng ${ }^{*}$ and Ravi Sharma
}

Nanyang Technological University, Singapore

\begin{abstract}
This paper investigates the financial performance of movies in China, a fast-growing commercial exhibition marketplace. Movie sales and Chinese market returns, movie characteristics and cultural contexts are operationalized in ordinary least squares (OLS) regression and quantile regression models to explain the highly varied acceptance across different products released since 2009. The samples comprise most of the widely released motion pictures in China. We posit that production budgets, sequels, audience ratings, cultural contexts and movie genres can significantly account for the variation in box office (BO) revenue and sales-revenue-to-cost (SRTC) within the Chinese market. Movies produced in countries with similar cultural contexts capture more audiences measured by box office proceeds, but it is noteworthy that SRTC falls at a decreasing rate as cultural differences increase. An increase in production budget generates more sales in China, but reduces the SRTC ratios with other factors controlled. Although aggregate cinema attendance may fluctuate with releasing date, this is not always true for an individual movie's financial success. Quantile regressions provide us with a richer characterization of the relationship, enabling us to analyze the entire distribution of box office proceeds and SRTC ratios, as well as their determinants at key quantiles.
\end{abstract}

Keywords: Box office revenue, market sales return, cultural discount.

\section{INTRODUCTION}

Buoyed by a sharp increase in cinema consumption, box office revenues ${ }^{1}$ in China $^{2}$ continued to surge in the first two quarters of 2013 (Brzeski and Tsui 2013). Homegrown movies made a material contribution to the sales growth. Their sales increased 1.11 billion U.S. dollars (6.85 billion China Yuan), a $144 \%$ year-on-year jump. The domestic sales of imported movies, however, decreased 675 million U.S. dollars (4.14 billion China Yuan), falling by $21.3 \%$ yearon-year (Brzeski and Tsui 2013). Although, in 2012, a new policy agreement between China and the United States allowed for 14 more 3D or IMAX movies to be imported, China has been attaching more importance to the support of homegrown movies. Since December $1^{\text {st }} 2012$, the Chinese government would subsidize the production and distribution of homegrown, "high-tech" movies featured by 3D and IMAX. For exhibition sectors, the State Council of China has subsidized the installation of digital screens and offers refunds for newly constructed theaters (EntGroup 2013a). Along with the fierce competition and golden opportunities within the international market, it is of utmost

*Address of correspondence to this author at the Nanyang Technological University, Singapore; Tel: +65 9397 6397; Fax: +65 6794 7682;

E-mail: ffeng002@e.ntu.edu.sg

${ }^{1}$ Box office revenues, box office sales and box office proceeds are used interchangeably in this paper.

${ }^{2}$ In this study, the Chinese box office sales refer to the revenues in mainland China market, which do not include the proceeds from Hong Kong, Macau and Taiwan markets. importance to have a comprehensive and in-depth understanding about the development of the movie industry in China. In this study, we examine the main determinants of movie sales in China, with a special emphasis on the culture perspective.

Although the Global Financial Crisis led to a decline in the movie business in most parts of the world since 2008 (Poupard 2008), however, 2009 was a boom year for box office sales in China (Su 2010). In 2012, China experienced a rapid growth in gross domestic product (GDP) with a total of 51.93 trillion China Yuan, increasing by $7.8 \%$ year-on-year, based on the data obtained from the Nation Bureau of Statistics of China (2012). The per capita annual disposable income (DPI) of urban households of 24,565 China Yuan was a real increase of $9.6 \%$ compared with the previous year. The sustained growth of GDP and DPI boosted personal consumption and allowed the movie business to flourish during these years. Several recent studies have paid special attention to Chinese films (Liebler, Jiang and Chen 2015; Zhou 2001; Yeh 2009). However, until now, few extant academic works involve the discussion of the movie industry in China from an economics perspective. In this regard, we contribute to the literature on movie sales by uncovering the factors affecting a movie's financial success in China.

Culturally, there is reason to believe that the type of movies shown in the Chinese market would differ from that of other markets due to the socio-economic differences. Given the increasing maturity of market circumstance and industrial regulation, understanding the financial performance of the theatrical releases in a 
burgeoning commercial exhibition market will make a significant sense for both industrial forecasting and managerial suggestions.

Several studies have examined the factors associated with the financial performance of theatrical movies. Factors widely used to account for the variation in box office sales include: demographic characteristics (Redondo and Holbrook 2010), cultural distance ( $\mathrm{Fu}$ and Lee 2008; Lee 2009; Walls and McKenzie 2012), seasonality effects (Cartier and Liarte, 2012), star power (Ravid 1999), budgets (Palia Ravid and Reisel 2008; Ravid 1999), professional reviews (Basuroy, Chatterjee and Ravid 2003), word of mouth referrals (Chintagunta, Gopinath and Venkataraman 2010; Liu 2006), sequel (Bruce, Foutz and Kolsarici 2012), genres (Desai and Basuroy 2005), and MPAA ratings (Ravid 1999; De Vany and Walls 2002). However, little scholarly discussion involved the indirect and nonlinear impact of cultural affinity on movie consumption behavior, and little research has been done to assess the movie performances across all the quantiles. This paper Contributes to this line of literature by showing a nonlinear effect of cultural similarity and using quantile regression technique to fully quantify the effect of determinants.

The rest of this paper is organized as follows. After this brief introduction in Section One, a review of the literature is the focus of the next section. In Section Three, hypotheses and research question are proposed. Section Four defines the variables, specifies the methods for quantitative analyses, describes the data, and provides the basic descriptive statistics. Section Five presents the findings and discusses the empirical results. The final section concludes.

\section{BRIEF LITERATURE REVIEW}

Movies have properties of art and economics. McKenzie (2012) offered a comprehensive review of the literature from an economic perspective. Movie revenues are unpredictable, even to insiders (Walls 2005a). Therefore, the status of the business is stochastic, and in many cases quite unpredictable, as reviewed by Brookey (2011). The budget allocated for movie production and distribution is sunk cost, which further hedges small companies from entering the movie industry. For example, in China, the top ten companies with the largest market shares in movie distribution accounted for $89.2 \%$ of the nationwide market in 2012 (EntGroup 2013a).

\subsection{Main Determinants of Box Office Revenue}

Since the 1990s, there has been a large body of research exploring the main determinants of box office revenue. Bagella and Becchetti (1999) analyzed the underlying determinants of box office success in Italy. Using statistical regression models, they showed that there was a significant relation between box office sales and the power of the director and cast (i.e. actors). Specifically, their study also showed a positive quadratic externality between the power of director and casting in predicting box office sales. Another interesting finding was that, ceteris paribus, production houses and movie genres had little significant marginal effects on the sale performance.

Ravid (1999) investigated the roles of movie stars, budgets, MPAA ratings, and sequels on influencing box office receipts and returns on investment for movies produced in the 1990s. He found a significant MPAA effect. He also found that stars had no influence on a film's financial success, whereas big budgets, high ratings, more reviews, and sequels are all contributive to the improvement of a film's financial performance. However, big budgets alone may not guarantee profitability.

By analyzing the weekly domestic box office revenues of 200 movies released from 1991 to 1993 , Basuroy et al. (2003) identified the critical reviews as a significant factor that influenced the movie performance. They found that, early in the lifecycle of theatrical movies, all the reviews were significantly associated with the box office performance with a negative bias of reviews. They also found that movie budget and star power imposed a moderation effect on the critical reviews, in a way that the impact of budget and star power was proportional to the negativepositive-ratio of a movie's critical reviews.

Chang and $\mathrm{Ki}$ (2005) explained the success of movies by using budget, star, sequel, genre (drama), $M P A A^{3}$ rating ( $P G$ and $R$ ), seasonality and opening week screens. They identified the effect of critic review as a predictor rather than an influencer. It has been also found that the intrinsic preferences of the audiences could better explain their consumption behavior.

${ }^{3}$ MPAA is the industry association known as the Motion Picture Association of America. 
Desai and Basuroy (2005) employed an ANOVA model to explain the impact of star power, genres, and critic reviews on the market performance of each movie. They explained the sales performance not only in response of the individual influence of star, reviews and genres, but also the interactive effects among those variables. Their study showed that the influences of star and reviews were weaker for the movies whose genres were of great interest to the audiences. The interactive effect between star power and critic reviews was empirically proved to be positive.

The model of Fu and Lee (2006) focused on the economic determination of box office performance of imported movies in Singapore and also discussed movie content parameters. In a later study, Fu and Lee (2008) examined how Singaporean movie-goers responded to international movies while considering the cultural and sociolinguistic differences between Singapore and countries of origin. For imported movies, the sales and GDP per capita of the exporting countries were positively correlated with the acceptance of Singaporean movie-goers. Cultural relationships among countries are key factors on influencing box office sales as well, since movie consumption takes place within a cultural context. The prevalence of Hollywood movies is explained as a consequence of cultural imperialism (Tomlinson 1991). The production budget was regarded as another quality indicator, which was also shown to be related to movie sales. They proposed that genres were jointly significant in influencing movie viewership given the evidence that the movie potpourri was bombarded with action, adventure and fiction blockbusters. By using Hofstede's cultural measurement (Hofstede 2013) to quantify and assess the cultural distance across the national boundaries, they explained that cultural affinity would further contribute to the oversea sales, which was consistent with previous findings (Craig Greene and Douglas 2005; Lee 2006; Lee 2008). Along this research line, an earlier research by Kim (2004) examined the dynamics of cultural discount and production expenditure in the Korean movie market. Fetscherin (2010) emphasized that a number of brand, product, distribution and consumer related variables had a significant influence on the opening week and accumulative box office sales in India.

Analyzing the expert reviews obtained from Gene Siskel and Roger Ebert, Reinstein and Snyder (2005) investigated how reviews would influence the opening weekend box office revenue. They find an influential effect of expert reviews which varied across different screen sizes and genres, with early positive reviews enlarging the entire magnitude of the viewership. They also found that expert reviews mattered more for dramas and narrowly released movies.

Some academic scholars have investigated the role of online word of mouth on movie sales. Liu (2006) found that the volume of word of mouth could significantly explain the weekly and aggregate box office revenue. Furthermore, Chintagunta, Gopinath, and Venkataraman (2010) found that the volume (valance) of word of mouth was the dominant driver of box office revenue at aggregated national (designated market area) level. Moon, Bergey and lacobucci (2010) separately explained the dynamic effects of professional critics and online reviews on movie revenues. They found that early box office revenue could promote subsequent ratings. Total box office revenue could be maximized through the combination of big budgets and high ratings. However, as time went by, movie-goers became more skeptical about critics and reviews due to an increasing movie-watching experience. Their empirical results also showed that movie sequels considering the massive fan bases were conducive to reaping more revenues.

Regarding the seasonality, Einav (2007) showed the endogeneity of observed seasonal patterns by separately analyzing the observed seasonal effect and underlying seasonal effect. He discerned that blockbusters tried to gain the competitive advantage by means of releasing when demand was high, amplifying the underlying seasonal effect. Hand and Judge (2011), however, found that the seasonal pattern was dominated by the underlying seasonal effect rather than market expansion effect.

In the movie industry, the bigger movies get bigger box office numbers and the winner takes most of the revenues. Walls's (2005b) research focused on the distribution of box office revenue. He used the logarithmic skew-normal and logarithmic skew-student$\mathrm{t}$ distribution to model the box office sales. Analyzing the data obtained from ACNielson EDI, he showed that movie business was inundated with extreme uncertainties.

These empirical studies on box office sales and international movie trade have largely examined the determination of movie trade strength and its sales performance. They have not investigated box office sales in the Chinese market and whether previous results are still valid. Whereas movie-goers may 
choose the theatrical releases based on a host of criteria, the questions about how they treat homegrown movies differently from imported ones and how cultural and economic factors are subject to the disparate attitudes remain unanswered. Whether there exists a non-linear relationship between financial performance and its determinants, is one question; and whether movie evaluation differs due to different treatments towards homegrown movies and imported ones, is another. Those effects discussed earlier are likely to be different for various levels of box office proceeds and sales-revenue-to-cost (SRTC). This examination of movie sales in China will shed light on these research gaps and contribute to this line of literature.

\subsection{Main Determinants of Box Office Profit}

By using different indexes to gauge the financial performance of theatrical released movies, some relevant findings are highlighted in this section. De Vany and Walls (2004) modeled the box office profit which was calculated by deducting the production cost from the estimated film rental. They found that the movie business was filled with uncertainties and proposed that one of the reasons was that movie-goers followed others because of the limited time and information they had. The impact imposed by early movie-goers on subsequent audiences was termed as bandwagon effect or herd behavior in economic and financial literature. They also found that production budget and star power were associated with the box office profit. Along this similar research line, $\mathrm{Bi}$ and Giles (2009) found that, given the same investment dollars, the possibility of gains was larger than the possibility of loss using the extreme value analysis.

Previous works primarily focused on estimating the influences of superstar and budget on box office profit or return on investment, and were still relatively silent about other variables, such as cultural factors. Due to the specific economic and market situation, box office sales and returns in the Chinese market may differ from those of other countries in a systemic way since its short history, rapid development, and restrictive institutional arrangement. This paper analyzes Chinese market returns, which is measured by SRTC and will be discussed in detail later. Although our SRTC concept is quite similar to the return on investment measure proposed by Ravid (1999) and Palia, Ravid, and Reisel (2008), and the profit measure used by Walls (2005b), the focus of our study, however, is the Chinese market sales of imported movies relative to its production cost instead of the measure which focused on domestic receipts. We contribute to the literature on box office returns by investigating the role of cultural similarities between China and western countries.

\section{MODEL AND HYPOTHESES}

In this section, five hypotheses and one research question will be proposed. They are based on two general themes: the determination of financial performance of theatrical released movies and the impact of cultural contexts on the international movie flows.

Well-constructed subject, plot and well-made audiovisual effect are possible reasons for the popularity of Hollywood movies. However, a cultural hurdle will arise along with the fact that imported movies require more effort to be understood due to the differences in languages and historical backgrounds. In China, national complex makes homegrown movies, or at least those movies with overlapping cultural features, more attractive for domestic consumers. Hypothesis 1a examines whether close cultural proximity promotes the box office revenue of a movie in China. ${ }^{4}$ However, the United States still remains the dominant influence on world culture, which has yet to be challenged. In spite of the striking dissimilarity between cultural contexts, Hollywood movies are well accepted by Chinese audiences in recent years. Reasons may include sophisticated plots and effects, an increasing fascination with the American culture, and the rise of English education all over the nation. Hence, the effect cultural proximity is predicted to be nonlinear. Hypothesis $1 \mathrm{~b}$ proposes that cultural affinity has a marginal diminishing effect on raising movie sales.

H1a: The China box office revenue of a movie will increase if its origin's cultural context is similar to China's.

H1b: An increase in cultural similarity increases the effectiveness of cultural affinity to increase revenue.

A mass of information is carried by the budget regarding a movie's star power, scenes, audiovisual effects, and post production. Thus, movie budget has been proposed as an ex-ante indicator of quality by

\footnotetext{
${ }^{4}$ Cultural context can also explain that China is the major market for Chinese movies and movies produced in Hong Kong and Taiwan, but not for Hollywood movies and European movies. However, incorporating a dummy variable to code Chinese movie may incur severe multicollinearity problem. We will conduct an analysis of the box office revenue only for imported movies to isolate this market share effect.
} 
movie-goers. Advertising budgets may also boost a movie's financial performance in that a movie is advertised to imply that it should be worth watching. Ravid (1999) assume that production budget was a constant proportion of total costs. Therefore, Hypothesis 2 only considers the impact of the production budget on the box office revenue. Although excluding the details on advertising budget and star power makes the model less complete, we will get a more accurate estimation of the effect of production budget on box office performance. It is unlikely that further information would fundamentally alter the conclusion in a systematic way.

H2: An increase in production budget will increase a movie's China box office revenue.

A movie sequel builds on its origin's financial success (Basuroy and Chatterjee 2008). A sequel has already enjoyed a massive fan base and familiarity in the potential market. Movie-goers tend to associate the quality of the original movie with the quality of the sequel because they categorize them as the same brand (Erdem, 1998). The advertisement expenditure for the original "hit" movie raises the brand awareness and the accumulative effect makes its sequel more likely than ever to succeed. Therefore, sequels are expected to reap more revenues than other movies. This is reflected in Hypothesis 3.

H3: The China box office revenue of a movie will be higher on average if it is a sequel.

Movies which are expected to perform well tend to be released when underlying cinema demand is high (Hand \& Judge, 2011). Conventionally, the underlying seasonal pattern is widely considered as an important factor that influences the releasing decision for distributors because people have more leisure time during vacations and holidays. However, at the same time, movies released at the time of peak demand get into an overly competitive market for target audiences. On the other hand, the releasing decision may, in turn, intensify the seasonal pattern in a way that additional demands are generated by more movies available for the audiences (Einav, 2007). In Hypothesis 4, we propose that, the upturns of box office sales in China coincide with the summer vacation, year-end/winter vacation and public holidays.

H4: The China box office revenue of a movie will increase during peak seasons.

Given the experiential and fashionable nature of theatrical released movies, audience rating serves as an indicator of word-of-mouth advertising and movie quality, and can critically influence subsequent acceptance (Liu 2006). With the help of Internet, everyone can share information with others and influence others' decision-making through word-ofmouth. Given limited time and information, most people are inclined to take advice from others because those people probably have ever experienced and know better. This makes average audience rating a sheer power in influencing box office sales. Hypothesis 5 considers the positive impact of audience average rating on the box office sales in Chinese market.

H5: A higher average audience rating will increase a movie's China box office revenue.

The genre of a movie is the most intuitive reference point for the audiences to understand the basic contents and formats. Audiences roughly categorize the movies based on their dramaturgic and aesthetic knowledge (Fu and Lee 2006). The China Movie-goer Survey Report conducted by EntGroup (2013b) showed that Chinese movie-goers had a fixed preference towards a certain set of genres. Action, comedy and sci-fi are most welcomed. In contrast, few audiences expressed interest in animation, documentary and drama. This research uses 21 categories to describe the type of movies: Adventure, Comedy, Drama, Action, Romance, Fantasy, Mystery, Thriller, Sci-fi, Animation, Family, Crime, Horror, War, History, Biography, Sport, Musical, Western, Documentary, and Music. The following research question aims to examine the impact of each movie genre on movie sales in the Chinese market.

RQ1: What movie genres affect the box office revenue, controlling for other factors?

\section{METHODS FOR QUANTITATIVE ANALYSES}

This section describes the variables used, data required, basic descriptive statistics, and regression models in validating $\mathrm{H} 1-\mathrm{H} 5$ and answering $\mathrm{RQ} 1$ with movies commercially released in China from January 2009 to July 2013, for a total of 55 months. ${ }^{5}$ Even though the period is rather short, our samples provide a representative collection of movies in China since the sample sizes (198 for all movies and 159 for imported

${ }^{5} 2008$ represents a structural break due to the Global Financial Crisis, moving the box office business toward a period of greater volatility. The observation period starts from 2009 to ensure that, from an economic and financial market perspective, box office data are drawn from the same distribution. 
movies) are large enough and the samples have covered five calendar years.

Movie titles were selected from "Box Office Statistics and Analysis" (http://www.tbzs.sinaapp.com/), which publishes data for movies released after 2000. Chinese authorities are highly secretive about box office data and this is the only accessible data source available for analysis. Only movies with a budget of 10 million US dollars or 30 million China Yuan and above ${ }^{6}$ are in the scope of our analysis. The sample selection in this study is more skewed towards big budget movies than is the case with others. The typical cut off is 1 million U.S. dollars (Ravid 1999) whereas here is it 10 million, since we do not have sufficient entries for some variables. The high budget cutoff is perhaps worrisome because small budgets sometimes lead to high returns (Ravid 1999). However, this is a limitation due to the available data. A total of 198 movies, among which 159 are imported ones, comprise the sample for our analysis ${ }^{7}$.

\subsection{Dependent Variables}

\section{Chinese Box Office Revenue \& Chinese Market Sales Revenue to Cost Ratio}

To investigate the financial performance of theatrical movies released in China, this research uses the box office revenue (BO) during the entire exhibition weeks as the dependent variable. The box office revenue is the real data which has been adjusted for the population increase and inflation. To test the robustness of the regression model, an alternative measurement has also been constructed as the Chinese market SRTC. It is constructed as the ratio of a movie's accumulative Chinese box office revenue to its estimated production budget. SRTC analysis only focuses on the imported movies. Homegrown movies naturally have significantly higher China market returns, which may lead to the model specification error since our samples come from two different

\footnotetext{
${ }^{6}$ Due to the low production costs of Chinese movies, titles with production budgets of 30 million China Yuan and above or equivalent amount of foreign currency are selected. Imported movies with budgets of 10 million US dollars and above or equivalent amount of foreign currency are recorded for examination.

${ }^{7}$ In fact, the percentage of Chinese movies is higher than indicated by the samples in this research. However, a large portion of Chinese movies which poorly performed do not have entries for such variables as production budget and audience ratings. Besides, their production budgets do not meet the sample selection criteria. Such movies are excluded from the data used in this paper. This paper focuses on movies with budgets above a certain benchmark mentioned above, although it may suffer from sample selection (survivorship) bias to some extent. Future study can modify this research with available data using stratified random sampling.
}

distributions. Box office figures are obtained from the website of Box Office Statistics and Analysis (http://www.tbzs.sinaapp.com/). The data sources of budget number and original country are available at IMDb (http://www.imdb.com/). According to IMDb, the movie budget is estimated on the basis of media reports and is often close to the cost of producing or shooting the film. The producing country is defined as the place where the production companies for that movie are based.

\subsection{Explanatory Variables}

\section{Cultural Distance}

Cultural Distance (CD) between China and the exporting country of a movie is operationalized to measure the effect of cultural affinity. Greet Hofstede delineated the national culture in terms of six dimensions (Hofstede 2013): power distance (PDI), individual versus collectivism (IDV), masculinity versus femininity (MAS), uncertainty avoidance (UAI), longterm versus short-term orientation (LTO), indulgence versus restraint (IVR). As some countries have no entries for LTO or IVR, only the first four dimensions are implemented to ensure a consistent measurement. The data are available at http://geerthofstede.com/countries.html for each country. For movie i, the cultural distance between its exporting country and China, $C D_{i}$ is computed as stated in Equation 1. It imposes a "square root" adjustment of Kogut and Singh's (1988) formula because cultural distance is a one-dimensional measure.

$$
C D_{i}=\left[\sum_{j=1}^{4} \frac{\left(I_{i j}-I_{C j}\right)^{2}}{V a r_{j}}\right]^{1 / 2}
$$

$I_{i j}$ and $I_{C j}$ are the indices for movie i's original country and China, in terms of the jth dimension. The difference between $I_{i j}$ and $I_{C j}(\mathrm{j}=1,2,3,4)$ measures the cultural dissimilarity regarding PDI, IDV, MAS and UAI. The variance is used to correct for the differences of scales across all the indices. For co-produced movies, we first calculate the cultural distance between each imported country and China, and then take the average. A series of similar quantification methods have been used in research on trade of movies or other media contents (Fu and Lee 2008; Lee 2009; McFadyen Hoskins and Finn 2004). The range of cultural distance is between zero and positive infinity. The larger the cultural distance, the more cultural discrepancies exist between China and a movie's original country or countries. 


\section{Budget}

The data on budgets (B) are obtained from the website of Internet Movie Database (IMDb). As in many cases, budget is considered as a business secret in the motion picture industry and therefore cannot be obtained for research purposes (Litman 1998). Hence, the budget data on IMDb are primarily based on estimation. Observations without budget entries are excluded from this analysis. Budget data are subject to inflation-related adjustment. Adjustment with regard to the population growth is also necessary because the larger the population, the higher the potential cinema demand, and the greater likelihood of a larger amount of budget (Fu and Lee 2006).

\section{Sequel}

The dummy variable SQ implies whether a movie is a sequel. The value is unity for a sequel and zero for an original movie. The data are obtained from the movies' descriptions on IMDb and the website of http://www.hollywood.com/.

\section{Seasonality}

An essential characteristic of cinema attendance is that cinema demand peaks around major holidays and vacations. Peak periods in China include Solar New Year, Lunar New Year, Tomb Sweeping Day, Labor Day, Dragon Boat Festival, Mid-autumn Festival, National Day, and Christmas. The summer recess (July and August) and year-end recess (January) are other peak periods because of the long school vacations for students. It is more likely for a movie to be financially successful if it is released during the peak attendance periods due to a higher underlying consumer demand across the year. By assuming that all the holidays and vacations have a same impact on the box office revenues, the seasonality variable (SS) is dummied as "1" if a movie is released during the peak periods, otherwise it is "0". The release dates in the Chinese market are collected from Mtime website (http://www.mtime.com/). This site lists the releasing date for each movie studied.

\section{Average Audience Rating}

Average Audience Rating (AAR) is widely regarded as an overall evaluation of movies by ordinary moviegoers. Our measures of audience rating come from two most popular movie comments website http://www.douban.com/ and http://www.mtime.com/. These are chosen for their comprehensive coverage. The overall assessments of each movie are rated by online users on a ten-point scale from 1 (awful) to 10 (excellent). We take the average of two assessments and get the AAR to reduce the evaluation bias. We also assume that average audience rating is a consistent indicator of movie quality. Professional reviews and critiques were shown to matter a great deal rather than just user reviews and ratings (Basuroy Chatterjee and Ravid 2003; Eliashberg and Shugan 1997). However, they will not be emphasized in this research since most of professional critical reviews are published on American websites and in English, to which Chinese movie-goers may not pay much attention.

\section{Movie Genres}

The genres $(\mathbf{G})$ of the sample movies are coded as a dichotomous dummy vector where the elements are taxonomised based on the categories obtained from IMDb. They are operationalized as an abstract generalization of a movie's content and are used to explain the variation in financial performances caused by different types of movie contents.

\subsection{Regression Models and Data Collection}

$B O_{i}$ and $S R T C_{i}$ are each regressed on $B_{i}, S Q_{i}, S S_{i}, A A R_{i}, C D_{i}, C D_{i}^{2}$ and $\boldsymbol{G}_{i}$ for 198 movies in the full sample analysis and 159 movies in the imported movie analysis. Variable abbreviations, descriptions and data sources are presented in Appendix A. Equations 2, 3 and 4 below describe the regression models.

$\ln B O_{i}=\alpha_{0}+\alpha_{1} \ln B_{i}+\alpha_{2} S Q_{i}+\alpha_{3} S S_{i}+\alpha_{4} \ln A A R_{i}+\alpha_{5} C D_{i}$ $+\alpha_{6} C D_{i}^{2}+\alpha_{7}^{\prime} G_{i}+\varepsilon_{i}, i$ from 1 to 198 for both homegrown and imported movies

$$
\begin{aligned}
& \ln B O_{j}=\beta_{0}+\beta_{1} \ln B_{j}+\beta_{2} S Q_{j}+\beta_{3} S S_{j}+\beta_{4} \ln A A R_{j}+\beta_{5} \ln C D_{j} \\
& +\beta_{6}\left(\ln C D_{j}\right)^{2}+\beta_{7}^{\prime} G_{j}+\mu_{j}, j \text { from } 1 \text { to } 159 \text { for only } \\
& \text { imported movies }
\end{aligned}
$$

$$
\begin{aligned}
& S R T C_{k}=\gamma_{0}+\gamma_{1} \ln B_{k}+\gamma_{2} S Q_{k}+\gamma_{3} S S_{k}+\gamma_{4} \ln A A R_{k}+\gamma_{5} \ln C D_{k} \\
& +\gamma_{6}\left(\ln C D_{k}\right)^{2}+\gamma_{7}^{\prime} G_{k}+\epsilon_{k}, k \text { from } 1 \text { to } 159 \text { for only } \\
& \text { imported movies }
\end{aligned}
$$

Standard OLS regressions above summarize the average relationships between groups of explanatory variables and dependent variables on the basis of conditional mean. This only provides a partial view of the relationship, as this research also seeks to delineate the relationship at different levels of box office proceeds and returns. In fact, the effects of explanatory variables may differ across different quantiles of the box office numbers. Furthermore, least 
Table 1: Descriptive Statistics of the Variables in BO Analysis of all Movies

\begin{tabular}{|c|c|c|c|c|c|}
\hline Variable & Obs & Mean & Std. Dev. & Min & Max \\
\hline \hline BO & 198 & 14788.74 & 18801.89 & 65 & 125893.5 \\
\hline B & 198 & 84973.7 & 67064.12 & 0 & 0 \\
\hline SQ & 198 & 0.2272727 & 0.4201325 & 0 & 1.5933 \\
\hline SS & 198 & 0.3232323 & 0.4688962 & 1 & 0 \\
\hline AAR & 198 & 7.010101 & 1.074496 & 0 & 4.15 \\
\hline CD & 198 & 2.881164 & 1.247363 & 0 & 19.03625 \\
\hline CDSQR & 198 & 9.849166 & 4.989385 & 055 \\
\hline
\end{tabular}

Note. (1) $\mathrm{BO}=$ the accumulative box office revenue in Chinese market for each movie denominated in 10000 China Yuan. (2) B = the production budget (negative cost) for each movie denominated in 1000 US dollars. (3) $S Q=$ whether a movie is a sequel $(Y e s=1, N o=0)$. (4) $S S=$ whether a movie was released during the public holidays and vacation periods (Yes = 1, No = 0). (5) AAR = the average audience rating obtained from the Website of Douban and Mtime. The range is from 0 to 10 . (6) $C D=$ the overall cultural distance between China and the imported countries for each movie. (7) CDSQR $=$ the square of cultural distance.

Table 2: Descriptive Statistics of the Variables in BO and SRTC Analysis of Imported Movies

\begin{tabular}{|c|c|c|c|c|c|}
\hline BO & 159 & 12820.09 & 17352.31 & 65 & 125893.5 \\
\hline SRTC & 159 & 0.1504847 & 0.2083554 & 0.0021667 & 1.730531 \\
\hline B & 159 & 98892.96 & 66013.32 & 651.5933 & 0 \\
\hline SQ & 159 & 0.2578616 & 0.4388396 & 0 & 1 \\
\hline SS & 159 & 0.2704403 & 0.4455907 & 3.45 & 9.15 \\
\hline AAR & 159 & 7.160063 & 0.99589 & 0.8038981 & 4.363055 \\
\hline CD & 159 & 3.456558 & 0.4008219 & 0.6462522 & 19.03625 \\
\hline
\end{tabular}

Note. (1) BO = the accumulative box office revenue in Chinese market for each movie denominated in 10000 China Yuan. (2) SRTC = box office revenue in Chinese market divided by production budget, which is defined as a movie"s Chinese market salesrevenue-to-cost ratio. The cost here refers to the estimated production budget or negative cost. (3) $B=$ the production budget (negative cost) for each movie denominated in $1000 \mathrm{US}$ dollars. (3) $\mathrm{SQ}=$ whether a movie is a sequel (Yes = 1 , No $=0$ ). (4) $S S=$ whether a movie was released during the public holidays and vacation periods $(Y e s=1$, No $=0)$. $(5)$ AAR $=$ the average audience rating obtained from the website of Douban and Mtime. The range is from 0 to 10. (6) CD = the overall cultural distance between China and the imported countries for each movie. (7) $C D S Q R=$ the square of cultural distance.

squares estimates can be severely distorted by atypical data points, especially for thick tailed disturbance distribution. Quantile regression with a semi-parametric or non-parametric specification of the model has the capability to accommodate those problems.

Tables 1 and 2 report the descriptive statistics for the variables modeled. Overall, the imported movies have a greater percentage of sequels, are more inclined to be released during off-peak periods because of institutional arrangement and political restrictions on movie importation. Imported movies also, on average, receive higher ratings due to their higher quality. The greater proportion of sequels implies that foreign movie markets are relatively more mature and their products have already built a larger scale of potential audiences. The superior movie quality does also result from a larger allocation for the production budget. Although the average box office revenue of mixed samples is much higher than that of the imported movies, the comparison here should be meaningless because of the different targeting markets for homegrown movies and imported ones. ${ }^{8}$

The zero-order correlation coefficients among the variables in BO analysis and SRTC analysis are listed in Tables 3 and 4. A movie's production budget is significantly related to other explanatory variables to some extent ${ }^{9}$, except for seasonal indicator. This implies that production budget is one of the key determinants of a movie's box office success.

\section{FINDINGS AND DISCUSSION}

\subsection{Ordinary Least Squares Regressions}

Table 5 reports the result of the BreuschPagan/Cook-Weisberg test for heteroskedasticity using

\footnotetext{
${ }^{8}$ The homegrown movies are primarily released in China, whereas market of imported movies mainly focuses on their domestic countries. Therefore, the comparison of Chinese market sales should be meaningless.

${ }^{9}$ The magnitudes of correlation coefficients range from .3280 to .4633 , and all are significant with $p<.001$
} 
Table 3: Zero-Order Correlations among the Variables in BO Analysis of all Movies

\begin{tabular}{|c|c|c|c|c|c|c|}
\hline & BO & B & SQ & ss & AAR & CD \\
\hline \multicolumn{7}{|l|}{$\mathrm{BO}$} \\
\hline B & $0.3214^{* * *}$ & & & & & \\
\hline$S Q$ & $0.3280^{\star * *}$ & $0.3262^{* * *}$ & & & & \\
\hline SS & $0.2278^{* *}$ & -0.0156 & 0.089 & & & \\
\hline AAR & $0.2673^{\star \star *}$ & $0.3443^{* * *}$ & $0.1602^{*}$ & 0.0167 & & \\
\hline$C D$ & $-0.2175^{\star *}$ & $0.4604^{* * *}$ & $0.1457^{*}$ & $-0.2342^{* *}$ & $0.2688^{* * *}$ & \\
\hline CDSQR & $-0.1918^{* *}$ & $0.4633^{* * *}$ & $0.1409^{*}$ & $-0.2212^{* *}$ & $0.2475^{\star * *}$ & $0.9864^{* * *}$ \\
\hline
\end{tabular}

Note. ${ }^{*} \mathrm{p}<.05 .{ }^{* *} \mathrm{p}<.01 .{ }^{* \star *} \mathrm{p}<.001$.

Table 4: Zero-Order Correlations among the Variables in BO and SRTC Analysis of Imported Movies

\begin{tabular}{|c|c|c|c|c|c|c|c|}
\hline & BO & SRTC & B & SQ & SS & AAR & CD \\
\hline \hline BO & & & & & & \\
\hline SRTC & $0.3488^{* * *}$ & & & & & \\
\hline B & $0.5245^{* * *}$ & -0.1509 & & & & \\
\hline SQ & $0.3338^{* * *}$ & 0.1043 & $0.2965^{* * *}$ & & & \\
\hline SS & 0.1262 & 0.0967 & 0.0937 & 0.1266 & & \\
\hline AAR & $0.3481^{* * *}$ & $0.2018^{*}$ & $0.2839^{* * *}$ & 0.1084 & 0.1158 & & \\
\hline CD & 0.0541 & $-0.5917^{* * *}$ & $0.2270^{* *}$ & 0.0282 & -0.0059 & -0.102 & -0.0687 \\
\hline CDSQR & 0.0431 & $-0.5268^{* * *}$ & $0.2145^{* *}$ & 0.0109 & -0.0075 & $0.9859^{* * *}$ \\
\hline
\end{tabular}

Note. ${ }^{*} \mathrm{p}<.05 .{ }^{* *} \mathrm{p}<.01 .{ }^{* * *} \mathrm{p}<.001$.

Table 5: Breusch-Pagan / Cook-Weisberg Test for Heteroskedasticity of BO Regression Using all Movies

\begin{tabular}{|c|c|c|}
\hline Ho: Constant variance & chi2 & Prob > chi2 \\
\hline Variables & 11.23 with $\mathrm{df}=1$ & 0.0008 \\
\hline \hline fitted values of $\ln \mathrm{BO}$ & 38.71 with $\mathrm{df}=27$ & 0.0673 \\
\hline RHS variables & & \\
\hline
\end{tabular}

the traditional OLS regression and we use a robust technique to estimate the standard errors of the coefficients. The result of $\mathrm{BO}$ regression for all movies is reported in Table 6 . The non-cultural factors ${ }^{10}$, cultural factors, and genres are sequentially entered into the regression.

To test $\mathrm{H} 1 \mathrm{a}$ and $\mathrm{H} 1 \mathrm{~b}$, the coefficients of $\mathrm{CD}$ and CDSQR $\left(C D^{2}\right)$ are significant and the signs are both consistent with expectation $(p=.000$ and $p=.005$, respectively). The key variable of interest is CDSQR which is used to capture the nonlinear effect. To elaborate this idea further, the cultural dissimilarity has

\footnotetext{
${ }^{10}$ The non-cultural factors do not include movie genres.
}

a negative effect on box office revenue. As the cultural distance increases, the marginal effect decreases at a constant rate, implying a nonlinear relationship between cultural distance and box office revenue. For example, if the cultural distance is 2 , a one-unit increase in cultural distance will reduce the box office revenue by $77.5 \%$. Alternatively, if the cultural distance becomes 3 , a one-unit increase in cultural distance will reduce the box office sales only by $30.3 \%$. One controversial issue here requires particular attention. If the movie is homegrown, namely the cultural distance equals to zero, a one-unit increase in cultural distance will reduce the box office sales by $171.9 \%$. This is inadmissible because box office revenue can never be negative. 
Table 6: Hierarchical Regression with Robust Estimation Testing the Predictors of Box Office Revenue of both Homegrown and Imported Movies (InBO)

\begin{tabular}{|c|c|c|c|}
\hline \multirow{2}{*}{$\begin{array}{l}\mathrm{N}=198 \\
\text { Variables }\end{array}$} & \multicolumn{3}{|c|}{$\ln B O$} \\
\hline & Coef. & $t$ & $\mathrm{D} R^{2}$ \\
\hline Non-Cultural & & & $0.218^{* * *}$ \\
\hline $\ln B$ & $0.600^{* * *}$ & 6.240 & \\
\hline SQ & $0.779^{\star \star *}$ & 5.500 & \\
\hline SS & 0.116 & 0.820 & \\
\hline Cultural & & & $0.292^{* * *}$ \\
\hline$C D$ & $-1.719^{* * *}$ & -6.690 & \\
\hline CDSQR & $0.236^{\star * *}$ & 3.880 & \\
\hline Genres & & & $0.124^{* * *}$ \\
\hline Drama & $-0.387^{*}$ & -2.220 & \\
\hline Action & 0.024 & 0.140 & \\
\hline Romance & -0.080 & -0.400 & \\
\hline Fantasy & 0.216 & 1.190 & \\
\hline Mystery & -0.127 & -0.640 & \\
\hline Thriller & 0.076 & 0.410 & \\
\hline Sci-Fi & $0.380^{*}$ & 2.260 & \\
\hline Animation & -0.452 & -1.530 & \\
\hline Family & -0.285 & -1.110 & \\
\hline Sport & 0.573 & 1.530 & \\
\hline Musical & 0.455 & 1.390 & \\
\hline Western & -0.550 & -0.760 & \\
\hline Documentary & 0.643 & 0.500 & \\
\hline Music & -2.358 & -1.850 & \\
\hline _cons & 1.220 & 0.930 & \\
\hline$R^{2}$ & & & 0.634 \\
\hline
\end{tabular}

Note. Reported unstandardized coefficients (Coef.) are for the final model in which all variables are entered. t-values are calculated based on the robust estimation of standard error. $\Delta R^{2}$ is defined as the increment to $R^{2}$. Namely, it is the change in the dependent variable"s variance explained by the additional variable block of explanatory variables. The block of Non-cultural factors first enters, followed by cultural block and genres block. The non-cultural block does not include genres. ${ }^{*} \mathrm{p}<.05 .{ }^{* *} \mathrm{p}<.01 .{ }^{* * *} \mathrm{p}<.001$.

Two explanations are offered here. First, the effect of cultural distance is evaluated controlling for other factors. It can be offset by the positive effects due to the increase in production budget and average audience rating. Table 3 shows that cultural distance is positively related to production budget (Corr. $=.4604, \mathrm{p}$ $=.000$ ) and average audience rating (Corr. $=.2688, p=$ $.000)$. Second, the negative influence of cultural distance can be amplified by the loss of market share, where the loss of market share is difficult to separately 
measure. The cultural distance hypothesis in our study automatically takes the market share effect into account, in a way that a small increase in cultural distance within its lower range makes a movie suffer severe market share loss in China. Nevertheless, the effect of first order term is consistent with the findings of movie sales in other countries, such as Singapore (Fu and Lee 2008). In China, all foreign movies suffer from such loss due to the dissimilarity between the cultural contexts. However, the positive sign of its quadratic term provides us with some new insights and implies a diminishing marginal effect. In other words, the U.S. "cultural imperialism" (Schiller 1992), the fascination with the American and European cultures, and the sophistication of imported media products may turn this situation around to a certain extent. The effect is statistically and economically significant. Therefore, our empirical results support $\mathrm{H} 1 \mathrm{a}$ and $\mathrm{H} 1 \mathrm{~b}$ accordingly, when modeling the whole set of observations.

For $\mathrm{H} 2$, increase in budget appreciably generates more box office revenue $(p=.000)$. A $1 \%$ increase in budget will bring $.6 \%$ more box office revenue on average. This result suggests that production budget is an indicator of a movie's quality and it is perceived as such by the movie-goers. Therefore, $\mathrm{H} 2$ is supported.

$\mathrm{SQ}$ also has a significantly positive influence on $\mathrm{BO}$ $(p=.000)$. The coefficient reads that the sequel will help a movie reap $117.93 \%$ greater box office revenue compared with other movies, on average, controlling for other factors. This suggests that a sequel's origin acts as an avenue of advertising and raises the brand awareness before the sequel's releasing. For the average movie-goers, movie brand dominates all other factors in their judgment of cultural products. On the other hand, the original movie helps to accumulate a large crowd of potential audiences, boosting the box office sales of its sequel during the opening day and opening week. Movies with financial success during the earlier stage will realize disproportionately greater movie-goer acceptance because the bandwagon effect contributes to amplify the initial success. The regression results lend strong support to $\mathrm{H} 3$.

On further analysis, it is noted that a movie released during peak season captures a higher level of box office success, but the effect is not statistically significant $(p=.414)$. It is likely that market expansion effect intensifies the competition among movies during the public holidays and vacation periods, making a greater amount of movie suppliers compete for a proportionally increased box office revenue. On the other hand, the underlying seasonal effect is not as strong as it was proved to be in previous studies (Einav 2007; Hand and Judge 2011). The consumers are inclined to be rational by avoiding consuming movies during the peak periods. Even when they do, they choose the best movie to watch due to limited time and income, which only makes the winners even more successful. Our results indicate that the agglomeration of supply and the increase in underlying demand do not necessarily increase the box office ranking of individual movies in a statistical sense. H4 is not supported.

The average audience rating retains a positive relationship with the natural log box office revenue and a strong level of statistical significance $(p=.000)$. The coefficient estimate implies that every $1 \%$ increase in average audience rating will attribute $1.88 \%$ more box office sales with other factors controlled. This large impact of "collective intelligence" implies a strong bandwagon effect and herd behavior among moviegoers in China. Conventional media economics suggests that movie quality is a significant determinant of cinema attendance and box office sales (Fu and Lee 2008). Internet accessibility makes online audience ratings a reasonable quality indicator for most people who know little before they actually watch the movie. $\mathrm{H} 5$ is therefore supported.

For RQ1, the empirical results indicate that "drama" generates significantly lower box office revenues, reducing revenues by $32.09 \%(p=.028)$, while "sci-fi" provides significantly higher box office revenues, boosting sales by $46.23 \%(p=.025)$. Therefore, it seems that "sci-fi" increases a movie's popularity in China, whereas "drama" decreases. Previous studies found that "family" movies did well (Lee 2008). However, we find a negative effect of family although it is not statistically significant $(p=.268)$, and that the result for "family" movies is consistent with Fu and Lee (2008). One possible reason is that, in China, people prefer to enjoy the sophistication of Dolby Stereo system and 3-D technique fabricated in "sci-fi" movies in the cinema but think that they can download and watch the "drama" and "family" movies at home.

To ensure the robustness of the preliminary regression model stated in section 4.1.3, regression results exclusively for imported movies (presented in Table 7) are examined. The results are qualitatively similar. In Model 1, the empirical results support $\mathrm{H} 2, \mathrm{H} 3$ and $\mathrm{H} 5$, but do not support $\mathrm{H} 1 \mathrm{a}, \mathrm{H} 1 \mathrm{~b}$ and $\mathrm{H} 4$, possibly due to multicollinearity or small sample size $(\mathrm{N}=159)$. Importantly, both the linear and quadratic effects of 


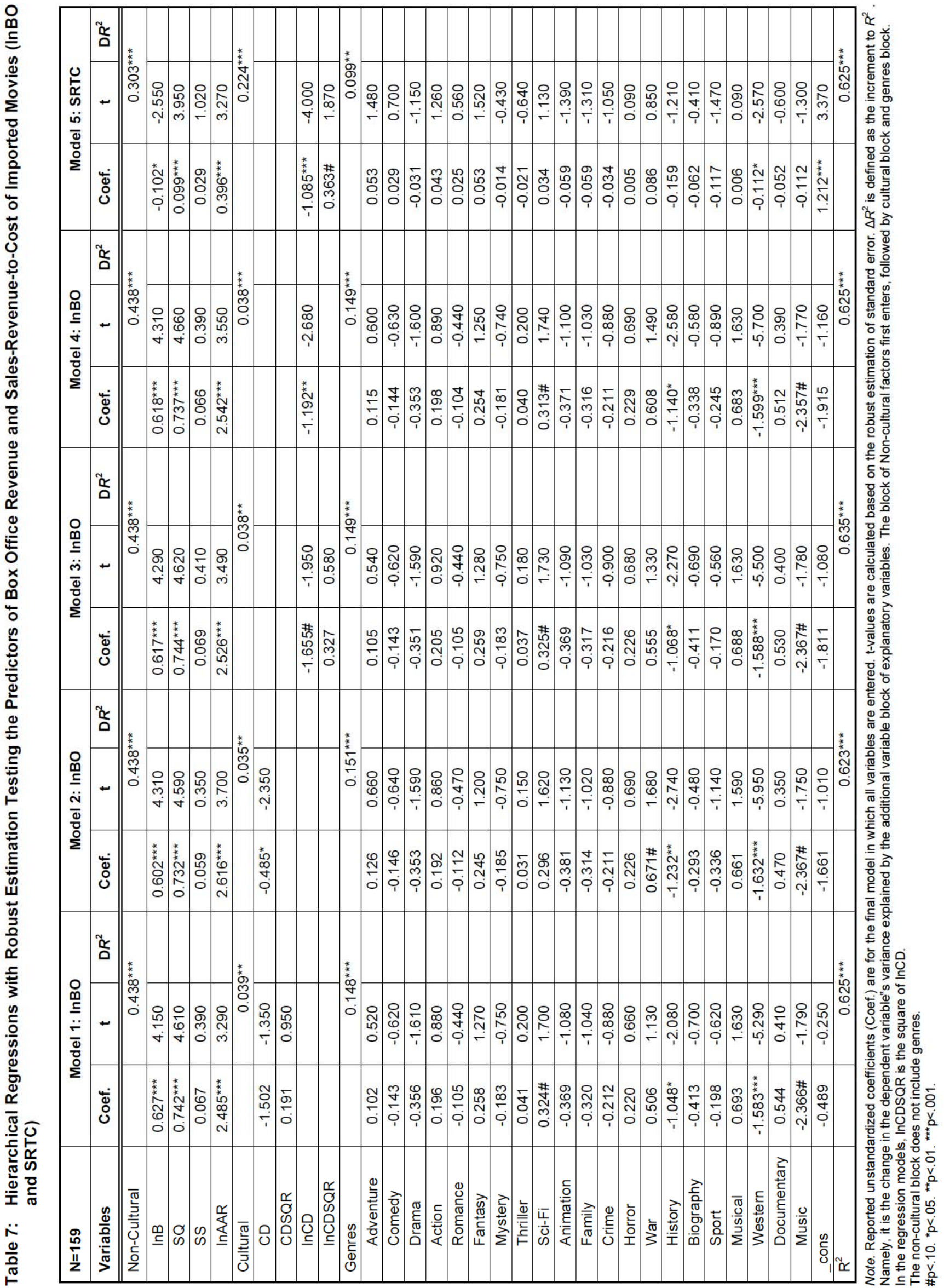


cultural distance on box office revenue are economically significant, and the magnitude of effects is comparable to the result in Table 6 .

Model 2 discards the quadratic term of cultural distance and the coefficient of CD becomes significant $(p=.020)$ with little changes in the coefficients of other variables. The reduction in the absolute value of cultural coefficients for both Model 1 and Model 2 implies that a considerable amount of loss of market share for imported movies is explained by the cultural distance effect when analyzing both imported and domestic movies as described earlier (Table 6). The regression results lend strong support to $\mathrm{H} 1 \mathrm{a}$.

In Model 3, the coefficient of squared log cultural distance becomes non-significant $(p=.565)$ and the coefficient of log cultural distance implies that $1 \%$ increase in cultural dissimilarity will lead to $1.655 \%$ decrease in box office revenue only with a moderate significance level $(p=.053)$. The VIFs of InCD and InCDSQR are 14.31 and 13.66, which again indicate the existence of multicollinearity. When only considering the linear term of natural-log cultural distance in Model 4, its coefficient suggests that a $1 \%$ increase in the differences between cultures will reduce the box office proceeds by $1.192 \%(p=.008)$. The results support $\mathrm{H} 1 \mathrm{a}$, but lend no support to $\mathrm{H} 1 \mathrm{~b}$.

For the genres block, all the models, from Model 1 to Model 4, suggest that "history", "western" and "music" generate significant lower box office sales while the positive influence of "war" is only supported by Model 2 with a moderate significance level. Model 1 , 3 and 4 lend support to the positive relationship between Sci-fi and box office revenue. This is significantly different from the finding using the complete set of movie titles, and indicates that Chinese audiences have different evaluation criteria regarding homegrown and imported movies.

Model 5 treats the Chinese market SRTC as the dependent variable and tests whether the results still hold. Both $\ln C D(p=.000)$ and , $(\ln C D)-2 .(p=.063)$ are significant, suggesting that, given a $1 \%$ change in cultural distance, Chinese market return on production investment will decrease by 1.085 if the cultural distance is one, and decrease by .582 if the cultural distance is two. This negative association attests to the influence of cultural dissimilarity on both box office revenues and overseas returns for imported movies. More importantly, the impact of cultural discount on SRTC is less effective for movies with greater differences in cultural contexts. Both $\mathrm{H} 1 \mathrm{a}$ and $\mathrm{H} 1 \mathrm{~b}$ are supported. It is worth noting that the coefficient of $\ln B$ is negative, implying that a $1 \%$ increase in negative cost tends to reduce the SRTC by an absolute value .102 ( $p$ $=.012$ ). This follows the uncertain success probabilities in motion picture industry proposed by Walls (2005b) and accords to the results obtained by Ravid (1999). In our setting, an increasing allocation for production budget increases the numerator of SRTC, but the denominator will not be able to meet the increasing rate of budget. $\mathrm{H} 2$ cannot be supported. Other results lend support to $\mathrm{H} 3$ and $\mathrm{H} 5$, but not H4. For RQ1, certain movie genres tend to generate lower SRTC. Western $(p=.011)$ movies are found, compared with others, to be inversely related to the SRTC. These findings again are different from those using box office revenue as the dependent variable, because revenues (BO) and returns (SRTC) are two different measures of performance. However, both conclusions mirror the movie-going trends for Chinese audiences, and perhaps Asian audiences as well.

Empirically, one of the most important contributions of our study is the diminished effect of cultural distance on movie financial performance, as evidenced by the positive coefficient on the quadratic terms CDSQR and InCDSQR. This non-linear effect is statistically effect in Table 6 (where dependent variable is natural-log box office revenue) and marginally significant in Model 5 of Table 7 (where dependent variable is sales-revenue-tocost) but not in Model 1 and Model 3 of Table 7, probably because of multicollinearity and/or small sample size. However, as we discussed earlier, the effect is economically significant in all four specifications. Theoretically, our results are consistent with the existence of a production function for movies such that the factor input, cultural affinity, enter with positive marginal products but with a diminishing marginal product. ${ }^{11}$ To elaborate, a simplified movie production function may have a Cobb-Douglas form, $Q=A B^{m} C^{n}$, where $\mathrm{A}$ is total-factor productivity, $\mathrm{B}$ is budget, and $C$ is cultural affinity. Our results are consistent with diminishing returns to scale where the $\mathrm{m}$ and $\mathrm{n}$ add up to less than one.

\subsection{Quantile Regressions}

Assuming the data are well behaved, the estimators obtained from quantile regression are asymptotically normally distributed. Figure 1 illustrates the empirical

\footnotetext{
${ }^{11}$ We thank the referee for suggesting this point.
} 


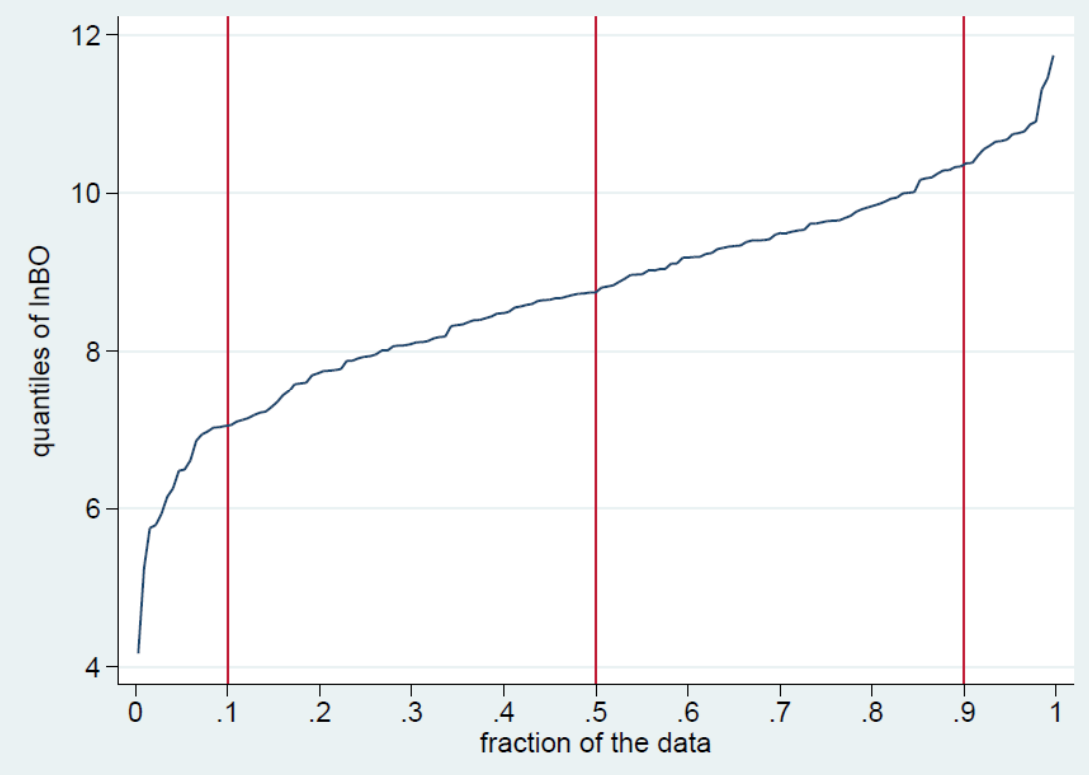

Figure 1: Empirical Cumulative Density Function of Natural-log Box Office Revenues.

cumulative density function of natural-log box office revenues. It is clear that the $10^{\text {th }}, 50^{\text {th }}$ and $90^{\text {th }}$ quantiles are roughly $7,8.75$, and 10.5 on a natural-log scale. Using the data on the natural-log box office revenues of imported movies, comparing the robust OLS estimates with the quantile regression estimates results in Table 8.

Note that the effects of explanatory variables differ to a certain extent across different quantiles. For movies whose box office revenues reside at lower quantiles, increase in production budget and such strategy as releasing during the seasonal peaks are effective approaches to generate higher box office revenues measured by percentage. The quantile regression results with regard to the production budget are consistent with those obtained by De Vany (2004). $\mathrm{He}$ found that increasing budgets and screens pushed up the lower quantiles of revenue far more than the upper quantiles. In our study, the contribution of production budget is reduced at upper quantiles with a strong significance level. On the other side, the cultural discount should be a great threat for movies with lower sales ( $p=.084$ for $10^{\text {th }}$ quantile). However, it will never be a barrier for a movie's sales overseas at upper quantiles $\left(p=.386\right.$ for $25^{\text {th }}$ quantile, $p=.534$ for $50^{\text {th }}$ quantile, $p=.614$ for $75^{\text {th }}$ quantile and $p=.605$ for $90^{\text {th }}$ quantile). This is consistent with earlier results that, for blockbusters, audiences pay more attention to the sophisticated plots and audiovisual effects, rather than the cultural compatibility. Sequel and average audience rating are always regarded as the indicators of movie quality across all the quantiles. Finally, out results indicate that the effects of movies genres are sensitive to model specification.

The equivalence of the estimates of non-genre variables across different quantiles was formally tested. However, the results of F-tests in Table 9 cannot reject all the null hypotheses that the coefficient estimates are equal across the key quantiles.

Figure 2 shows the empirical cumulative density function of SRTC ratios. All the key quantiles are below .5 , indicating the inequality of returns in the movie business, in which the winners take all. When using SRTC as the dependent variable, Table $\mathbf{1 0}$ shows that production budget is inversely related to the SRTC across all the quantiles, and the impact is especially intense and significant at upper quantiles. However, on the other hand, for movies with higher SRTC, sequel and average audience rating have a greater positive impact accordingly. As a general rule, negative effects imposed by larger negative cost can be reversed by the positive effects brought by sequel and higher average audience rating to some degree. It is noteworthy that movies with greater cultural discount effect have significantly lower SRTCs at $50^{\text {th }}$ quantile and below (Coef. $\operatorname{lnCD}=-1.476$ with $p=.000$, Coef. $\operatorname{lnCDSQR}=$ .576 with $p=.000$ at $10^{\text {th }}$ quantile; Coef. $\ln C D=-1.486$ with $p=.000$, Coef. InCDSQR $=.607$ with $p=.000$ at $25^{\text {th }}$ quantile; Coef. $\operatorname{InCD}=-1.361$ with $\mathrm{p}=.000$, Coef. $\operatorname{lnCDSQR}=.591$ with $\mathrm{p}=.000$ at $50^{\text {th }}$ quantile), but it is less strong and not statistically significant at $75^{\text {th }}$ quantile and $90^{\text {th }}$ quantile (for InCD and InCDSQR, $p=$ $.405, p=.696$ at $75^{\text {th }}$ quantile, and $p=.109, p=.537$ at 
Table 8: Robust Ordinary Least Squares Regression and Quantile Regressions Testing the Predictors of Box Office Revenue of Imported Movies (InBO)

\begin{tabular}{|c|c|c|c|c|c|c|c|c|c|c|c|c|}
\hline \multirow{2}{*}{$\begin{array}{l}\mathrm{N}=159 \\
\text { Variables }\end{array}$} & \multicolumn{2}{|c|}{ OLS robust } & \multicolumn{2}{|c|}{ QR 10th quantile } & \multicolumn{2}{|c|}{ QR 25th quantile } & \multicolumn{2}{|c|}{ QR 50th quantile } & \multicolumn{2}{|c|}{ QR 75th quantile } & \multicolumn{2}{|c|}{ QR 90th quantile } \\
\hline & Coef. & $t$ & Coef. & $t$ & Coef. & $t$ & Coef. & $t$ & Coef. & $t$ & Coef. & $t$ \\
\hline \multicolumn{13}{|l|}{ Non-Cultural } \\
\hline $\ln B$ & $0.617^{* * *}$ & 4.290 & $0.963^{* * *}$ & 10.820 & $0.590^{* * *}$ & 3.730 & $0.524^{* * *}$ & 3.270 & $0.427^{\star *}$ & 2.990 & $0.339^{* * *}$ & 3.300 \\
\hline SQ & $0.744^{* * *}$ & 4.620 & $0.824^{*}$ & 6.120 & $1.016^{* * *}$ & 4.240 & $0.794^{* * *}$ & 3.280 & $0.628^{* *}$ & 2.900 & $0.608^{* * *}$ & 3.910 \\
\hline SS & 0.069 & 0.410 & $0.283^{*}$ & 2.300 & 0.158 & 0.720 & -0.036 & -0.160 & 0.157 & 0.800 & 0.060 & 0.420 \\
\hline InAAR & $2.526^{* * *}$ & 3.490 & $3.172^{\star \star \star}$ & 6.860 & $2.458^{\star *}$ & 2.990 & $2.800^{* * *}$ & 3.370 & $2.098^{* *}$ & 2.830 & $2.830^{* * *}$ & 5.300 \\
\hline \multicolumn{13}{|l|}{ Cultural } \\
\hline $\operatorname{lnCD}$ & $-1.655 \#$ & -1.950 & $-1.926 \#$ & -1.740 & -1.707 & -0.870 & -1.238 & -0.620 & -0.897 & -0.510 & -0.662 & -0.520 \\
\hline InCDSQR & 0.327 & 0.580 & -0.825 & -1.140 & -0.036 & -0.030 & 0.019 & 0.010 & 0.701 & 0.600 & 0.901 & 1.080 \\
\hline \multicolumn{13}{|l|}{ Genres } \\
\hline Adventure & 0.105 & 0.540 & 0.107 & 0.710 & 0.195 & 0.730 & 0.006 & 0.020 & -0.033 & -0.140 & -0.174 & -1.000 \\
\hline Comedy & -0.143 & -0.620 & -0.311 & -1.620 & 0.074 & 0.220 & -0.188 & -0.550 & -0.342 & -1.110 & 0.017 & 0.080 \\
\hline Drama & -0.351 & -1.590 & $-0.511^{* * *}$ & -3.570 & -0.401 & -1.570 & -0.274 & -1.060 & $-0.414 \#$ & -1.800 & $-0.481^{* *}$ & -2.900 \\
\hline Action & 0.205 & 0.920 & 0.163 & 1.050 & 0.302 & 1.100 & 0.433 & 1.560 & 0.083 & 0.330 & 0.284 & 1.590 \\
\hline Romance & -0.105 & -0.440 & $0.397 \#$ & 1.970 & -0.319 & -0.890 & 0.007 & 0.020 & -0.356 & -1.100 & 0.079 & 0.340 \\
\hline Fantasy & 0.259 & 1.280 & $0.487^{*}$ & 3.250 & 0.345 & 1.290 & 0.433 & 1.610 & -0.028 & -0.110 & $0.358^{*}$ & 2.070 \\
\hline Mystery & -0.183 & -0.750 & -0.006 & -0.030 & 0.058 & 0.180 & 0.086 & 0.260 & $-0.504 \#$ & -1.720 & $-0.458^{*}$ & -2.170 \\
\hline Thriller & 0.037 & 0.180 & 0.170 & 1.120 & 0.095 & 0.350 & -0.002 & -0.010 & -0.084 & -0.340 & -0.283 & -1.610 \\
\hline Sci-Fi & 0.325\# & 1.730 & 0.162 & 1.140 & 0.217 & 0.860 & $0.541^{*}$ & 2.120 & 0.157 & 0.690 & 0.167 & 1.020 \\
\hline Animation & -0.369 & -1.090 & $-0.572^{*}$ & -2.420 & -0.441 & -1.050 & -0.415 & -0.970 & -0.544 & -1.430 & 0.129 & 0.470 \\
\hline Family & -0.317 & -1.030 & $-0.385 \#$ & -1.830 & $-0.684 \#$ & -1.820 & -0.231 & -0.610 & -0.186 & -0.550 & $-0.688^{* *}$ & -2.820 \\
\hline Crime & -0.216 & -0.900 & -0.069 & -0.340 & -0.198 & -0.560 & -0.141 & -0.390 & -0.507 & -1.570 & $-0.789^{* * *}$ & -3.410 \\
\hline Horror & 0.226 & 0.680 & $0.577^{*}$ & 2.020 & 0.280 & 0.550 & 0.204 & 0.400 & -0.086 & -0.190 & -0.213 & -0.640 \\
\hline War & 0.555 & 1.330 & $2.252^{* * *}$ & 4.980 & 0.848 & 1.050 & 1.089 & 1.340 & -0.265 & -0.370 & -0.674 & -1.290 \\
\hline History & $-1.068^{*}$ & -2.270 & $-2.695^{\star * \star *}$ & -5.370 & -1.107 & -1.240 & $-1.600 \#$ & -1.770 & -0.253 & -0.310 & 0.089 & 0.150 \\
\hline Biography & -0.411 & -0.690 & $3.111^{* * *}$ & 4.220 & 0.346 & 0.260 & 0.230 & 0.170 & $-2.627^{*}$ & -2.220 & $-3.481^{* * *}$ & -4.090 \\
\hline Sport & -0.170 & -0.560 & 0.197 & 0.280 & 0.337 & 0.270 & -0.468 & -0.370 & -0.330 & -0.290 & -0.668 & -0.820 \\
\hline Musical & 0.688 & 1.630 & $1.172^{*}$ & 2.400 & 1.275 & 1.470 & 0.321 & 0.360 & 0.366 & 0.470 & -0.504 & -0.890 \\
\hline Western & $-1.588^{* * *}$ & -5.500 & -0.356 & -0.520 & -0.865 & -0.710 & -1.270 & -1.030 & $-2.502^{*}$ & -2.280 & $-2.779^{* * *}$ & -3.530 \\
\hline Documentary & 0.530 & 0.400 & -0.027 & -0.050 & -0.285 & -0.290 & -0.684 & -0.690 & $-2.005^{\star}$ & -2.250 & $-2.340^{* * *}$ & -3.660 \\
\hline Music & $-2.367 \#$ & -1.780 & $-2.397^{\star \star \star}$ & -4.330 & $-3.134^{\star *}$ & -3.180 & 0.556 & 0.560 & 0.440 & 0.490 & 0.238 & 0.370 \\
\hline cons & -1.811 & -1.080 & $-6.012^{* * *}$ & -5.420 & -1.473 & -0.750 & -1.665 & -0.830 & 0.814 & 0.460 & 0.111 & 0.090 \\
\hline$R^{2}$ & $0.635^{\star * *}$ & & 0.528 & & 0.447 & & 0.402 & & 0.414 & & 0.469 & \\
\hline
\end{tabular}

Note. In the regression models, the non-cultural block does not include genres.

$\mathrm{R}$ squares reported for quantile regressions are Pseudo $\mathrm{R}$ squares.

$\# p<.10 .{ }^{\star} p<.05 .{ }^{\star *} p<.01 .{ }^{* \star \star} p<.001$.

Table 9: Test for the Equivalence of the Estimates of Non-Genre Variables across Different Quantiles Dependent Variable: InBO

\begin{tabular}{|c|c|c|}
\hline Null hypothesis & F statistics & p-value \\
\hline test $[q 10=q 25=q 50=q 75=q 90]: \ln B$ & $F(4,131)=1.77$ & 0.1380 \\
\hline test $[q 10=q 25=q 50=q 75=q 90]: S Q$ & $F(4,131)=0.65$ & 0.6252 \\
\hline test $[q 10=q 25=q 50=q 75=q 90]: S S$ & $F(4,131)=0.63$ & 0.6415 \\
\hline test $[q 10=q 25=q 50=q 75=q 90]: \ln A A R$ & $F(4,131)=0.56$ & 0.6911 \\
\hline test $[q 10=q 25=q 50=q 75=q 90]: \ln C D$ & $F(4,131)=0.02$ & 0.9994 \\
\hline
\end{tabular}




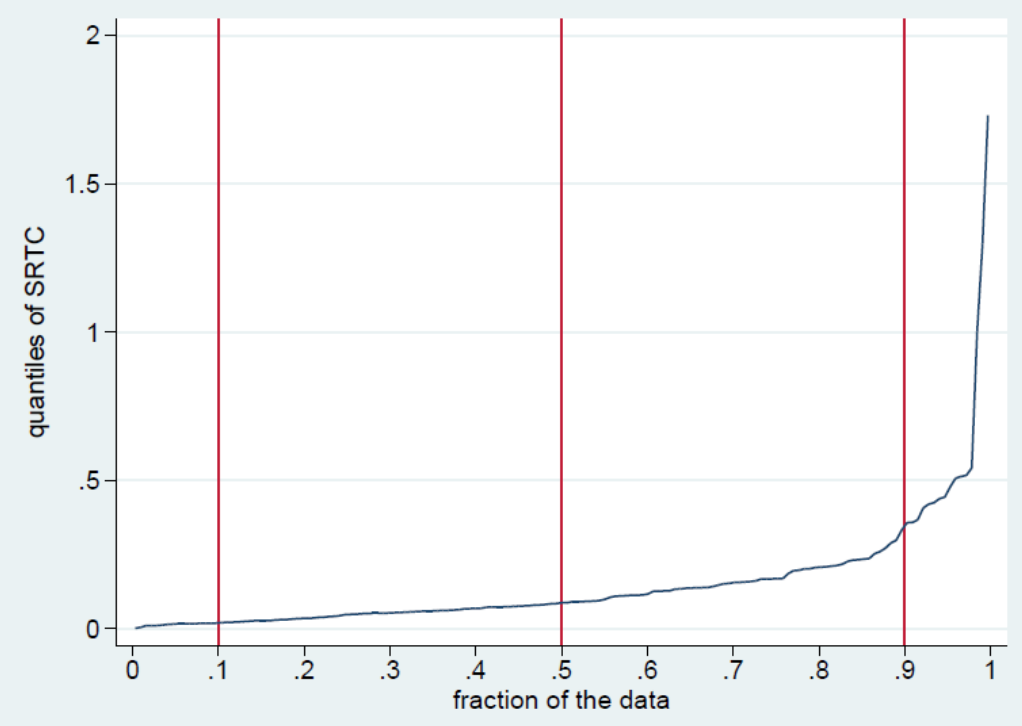

Figure 2: Empirical Cumulative Density Function of Sales-Revenue-to-Cost.

Table 10: Robust Ordinary Least Squares Regression and Quantile Regressions Testing the Predictors of SalesRevenue-to-Cost Ratios of Imported Movies (SRTC)

\begin{tabular}{|c|c|c|c|c|c|c|c|c|c|c|c|c|}
\hline \multirow{2}{*}{$\begin{array}{c}\mathrm{N}=159 \\
\text { Variables }\end{array}$} & \multicolumn{2}{|c|}{ OLS robust } & \multicolumn{2}{|c|}{ QR 10th quantile } & \multicolumn{2}{|c|}{ QR 25th quantile } & \multicolumn{2}{|c|}{ QR 50th quantile } & \multicolumn{2}{|c|}{ QR 75th quantile } & \multicolumn{2}{|c|}{ QR 90th quantile } \\
\hline & Coef. & $t$ & Coef. & $t$ & Coef. & $t$ & Coef. & $t$ & Coef. & $t$ & Coef. & $\mathbf{t}$ \\
\hline \multicolumn{13}{|l|}{ Non-Cultural } \\
\hline $\ln B$ & $-0.102^{*}$ & -2.550 & -0.003 & -0.730 & -0.005 & -0.650 & $-0.047^{\star}$ & -2.570 & $-0.120^{* * *}$ & -3.350 & $-0.200^{* * *}$ & -6.160 \\
\hline SQ & $0.099^{* * *}$ & 3.950 & $0.028^{*}$ & 4.920 & $0.056^{* * *}$ & 4.490 & $0.072^{* *}$ & 2.610 & 0.073 & 1.350 & $0.103^{*}$ & 2.090 \\
\hline SS & 0.029 & 1.020 & 0.007 & 1.420 & -0.002 & -0.140 & 0.010 & 0.400 & 0.004 & 0.080 & 0.022 & 0.480 \\
\hline InAAR & $0.396^{* * *}$ & 3.270 & $0.064^{* * *}$ & 3.310 & 0.063 & 1.480 & $0.293^{\star *}$ & 3.110 & $0.474^{*}$ & 2.550 & $0.587^{* * *}$ & 3.490 \\
\hline \multicolumn{13}{|l|}{ Cultural } \\
\hline $\ln C D$ & $-1.085^{\star \star *}$ & -4.000 & $-1.476^{* * *}$ & -31.830 & $-1.486^{* * *}$ & -14.620 & $-1.361^{* * *}$ & -6.040 & -0.371 & -0.840 & -0.650 & -1.610 \\
\hline InCDSQR & $0.363^{*}$ & 1.870 & $0.576^{* * *}$ & 18.960 & $0.607^{* * *}$ & 9.100 & $0.591^{* * *}$ & 4.000 & -0.114 & -0.390 & 0.163 & 0.620 \\
\hline \multicolumn{13}{|l|}{ Genres } \\
\hline Adventure & 0.053 & 1.480 & 0.015 & 2.400 & 0.010 & 0.730 & 0.012 & 0.400 & 0.069 & 1.150 & 0.007 & 0.130 \\
\hline Comedy & 0.029 & 0.700 & -0.013 & -1.550 & -0.017 & -0.960 & -0.004 & -0.100 & -0.033 & -0.420 & -0.082 & -1.170 \\
\hline Drama & -0.031 & -1.150 & -0.014 & -2.380 & -0.012 & -0.870 & -0.006 & -0.200 & -0.027 & -0.470 & -0.062 & -1.180 \\
\hline Action & 0.043 & 1.260 & 0.012 & 1.780 & 0.017 & 1.160 & 0.038 & 1.220 & 0.031 & 0.510 & $0.096 \#$ & 1.700 \\
\hline Romance & 0.025 & 0.560 & 0.023 & 2.680 & 0.018 & 0.980 & -0.014 & -0.350 & -0.040 & -0.500 & 0.007 & 0.090 \\
\hline Fantasy & 0.053 & 1.520 & 0.017 & 2.690 & 0.012 & 0.880 & 0.050 & 1.620 & -0.020 & -0.330 & 0.025 & 0.460 \\
\hline Mystery & -0.014 & -0.430 & 0.009 & 1.200 & 0.005 & 0.320 & -0.009 & -0.250 & -0.048 & -0.650 & -0.106 & -1.590 \\
\hline Thriller & -0.021 & -0.640 & 0.006 & 0.950 & -0.007 & -0.480 & 0.024 & 0.770 & -0.016 & -0.260 & $-0.210^{* * *}$ & -3.780 \\
\hline Sci-Fi & 0.034 & 1.130 & 0.009 & 1.520 & 0.023\# & 1.760 & $0.062^{*}$ & 2.140 & -0.002 & -0.030 & 0.068 & 1.320 \\
\hline Animation & -0.059 & -1.390 & -0.010 & -0.980 & -0.013 & -0.610 & -0.068 & -1.400 & -0.099 & -1.040 & 0.028 & 0.330 \\
\hline Family & -0.059 & -1.310 & -0.011 & -1.280 & -0.018 & -0.940 & 0.004 & 0.090 & -0.017 & -0.200 & -0.105 & -1.370 \\
\hline Crime & -0.034 & -1.050 & 0.002 & 0.220 & 0.028 & 1.520 & -0.027 & -0.660 & -0.101 & -1.250 & -0.090 & -1.230 \\
\hline Horror & 0.005 & 0.090 & $0.020 \#$ & 1.700 & $0.053^{*}$ & 2.000 & -0.015 & -0.250 & -0.025 & -0.220 & $-0.216^{*}$ & -2.070 \\
\hline War & 0.086 & 0.850 & $0.059^{* *}$ & 3.110 & 0.054 & 1.290 & 0.096 & 1.040 & -0.072 & -0.390 & -0.257 & -1.560 \\
\hline
\end{tabular}


(Table 10). Continued.

\begin{tabular}{|c|c|c|c|c|c|c|c|c|c|c|c|c|}
\hline \multirow{2}{*}{$\begin{array}{c}\mathrm{N}=159 \\
\text { Variables }\end{array}$} & \multicolumn{2}{|c|}{ OLS robust } & \multicolumn{2}{|c|}{ QR 10th quantile } & \multicolumn{2}{|c|}{ QR 25th quantile } & \multicolumn{2}{|c|}{ QR 50th quantile } & \multicolumn{2}{|c|}{ QR 75th quantile } & \multicolumn{2}{|c|}{ QR 90th quantile } \\
\hline & Coef. & $\mathbf{t}$ & Coef. & $\mathbf{t}$ & Coef. & $\mathbf{t}$ & Coef. & $\mathbf{t}$ & Coef. & $\mathbf{t}$ & Coef. & $\mathbf{t}$ \\
\hline History & -0.159 & -1.210 & $-0.072^{* *}$ & -3.420 & $-0.081 \#$ & -1.760 & -0.085 & -0.830 & -0.006 & -0.030 & 0.235 & 1.290 \\
\hline Biography & -0.062 & -0.410 & $0.098^{*}$ & 3.160 & 0.077 & 1.140 & -0.016 & -0.110 & -0.385 & -1.300 & $-0.933^{* * *}$ & -3.480 \\
\hline Sport & -0.117 & -1.470 & 0.017 & 0.560 & -0.005 & -0.080 & -0.060 & -0.420 & -0.326 & -1.150 & $-0.483 \#$ & -1.870 \\
\hline Musical & 0.006 & 0.090 & $0.071^{* *}$ & 3.460 & 0.050 & 1.120 & 0.019 & 0.190 & -0.025 & -0.130 & -0.150 & -0.840 \\
\hline Western & $-0.112^{*}$ & -2.570 & 0.002 & 0.070 & -0.017 & -0.270 & -0.062 & -0.440 & -0.268 & -0.980 & -0.365 & -1.470 \\
\hline Documentary & -0.052 & -0.600 & 0.026 & 1.130 & 0.015 & 0.300 & -0.061 & -0.540 & -0.301 & -1.350 & $-0.487^{*}$ & -2.410 \\
\hline Music & -0.112 & -1.300 & -0.004 & -0.160 & -0.022 & -0.430 & 0.044 & 0.390 & 0.079 & 0.350 & 0.034 & 0.170 \\
\hline _cons & $1.212^{\star * *}$ & 3.370 & 0.850 & 18.270 & $0.869^{* \star *}$ & 8.510 & $0.750^{\star * *}$ & 3.310 & $1.252^{\star *}$ & 2.810 & $2.022^{* * *}$ & 5.000 \\
\hline$R^{2}$ & $0.625^{\star * *}$ & & 0.246 & & 0.244 & & 0.268 & & 0.365 & & 0.565 & \\
\hline
\end{tabular}

Note. In the regression models, the non-cultural block does not include genres. $\mathrm{R}$ squares reported for quantile regressions are Pseudo $\mathrm{R}$ squares.

$\# p<.10 .{ }^{*} p<.05 .{ }^{* *} p<.01 .{ }^{* * *} p<.001$.

Table 11: Test for the Equivalence of the Estimates of Non-Genre Variables across Different Quantiles Dependent Variable: SRTC

\begin{tabular}{|c|c|c|}
\hline Null hypothesis & F statistics & p-value \\
\hline test $[q 10=q 25=q 50=q 75=q 90]: \ln B$ & $F(4,131)=2.00$ & 0.0986 \\
\hline test $[q 10=q 25=q 50=q 75=q 90]: S S$ & $F(4,131)=0.26$ & 0.9038 \\
\hline test $[q 10=q 25=q 50=q 75=q 90]: \ln A A R$ & $F(4,131)=3.23$ & 0.0144 \\
\hline test $[q 10=q 25=q 50=q 75=q 90]: \operatorname{lnCDSQR}$ & $F(4,131)=0.43$ & 0.7848 \\
\hline
\end{tabular}

$90^{\text {th }}$ quantile). The results corroborate that the cultural hurdle is less significant in impairing the Chinese market returns for movies with higher SRTC ratios.

For SRTC quantile regressions, the test for the equivalence of the estimates of non-genre variables across different quantiles is displayed in Table 11. The results significantly reject the equality of the estimated coefficients for natural-log average audience rating $(p=$ .0144), and reject the equivalence of the coefficient estimates of natural-log budget with a moderate significance level $(p=.0986)$. Online word of mouth and collective intelligence are especially effective in improving the Chinese market return on production investment across the upper quantiles.

\section{CONCLUSIONS AND FUTURE WORK}

This research is an exploratory investigation of the financial performance of movies released in China. It has drawn a nuanced but comprehensive picture of the Chinese movie industry. The introduction of such ingredients as the comprehensive exploration across all levels of financial performance by virtue of the quantile regression, and the detailed investigation of the cultural contexts will add to the richness and variety of media economics research on movie business.

Theoretically, our findings imply a nonlinear effect of cultural dissimilarity on a movie's Chinese market return. Media economics scholars should recognize the possible nonlinear and interactive influences imposed by factors and how the explanatory variables may disproportionally affect the movie financial success across different quantiles. Quantile regression should be a useful instrument for scholars to investigate the financial performance of media products in detail. Besides, the results are bound to vary according to model specifications as implied in Table 7.

For industry, the research findings are helpful for movie producers, distributors and exhibitors to make appropriate investment strategies. Under the institutional arrangement such as the movie import 
quota, distributors should select which movies to exhibit in the Chinese market after careful consideration. They should know how to seize the opportunities along with the emerging challenges in the rapidly growing market, how to improve the competitiveness of their products, and how to analyze the needs and tastes of their audiences. More specifically, producers and distributors should pay particular attention to the movies with high box office revenues and SRTCs. They should be clear about why such movies have a ready market, i.e., opening day/week box office proceeds. The choice of movies and screenings can be tailored to the needs and preferences of the audiences from the initial of movie projections. However, a blind budget allocation for movie production would be unwise. One can use big budgets to insure against catastrophically low revenues, but a blockbuster cannot be seeded through this strategy.

It will be insightful for future research to construct a life table and conduct a corresponding survival analysis to figure out how theatrical releases play out in the Chinese exhibition market across time. These can be compared directly to similar analyses done for the U.S., Hong Kong, Australian, and other markets. It would also be interesting to investigate the institutional characteristics of China's movie market and their impact on movie importation and financial performance. These would complement our discussion of the financial success and shed light on the main features of the distribution and exhibition contracts.

\section{APPENDIX A}

Data Sources of the Variables for Movie Analysis

\begin{tabular}{|c|c|c|}
\hline Variable Abbreviation & Variable Description & Data Source \\
\hline $\mathrm{BO}$ & Box office revenue & http://www. tbzs.sinaapp.com/ \\
\hline SQ & Sequel & $\begin{array}{l}\text { Internet Movie Database (IMDb) } \\
\text { http://www.hollywood.com/ }\end{array}$ \\
\hline CD & Cultural distance & http://geert-hofstede.com/countries.html \\
\hline \multirow[t]{2}{*}{$\mathrm{G}$} & Movie genres & Internet Movie Database (IMDb) \\
\hline & Producing country & Internet Movie Database (IMDb) \\
\hline
\end{tabular}

\section{REFERENCES}

Bagella, M. and Becchetti, L. 1999. "The Determination of Motion Picture Box Office Performance: Evidence from Movies Produced in Italy." Journal of Cultural Economics 23: 237256

http://dx.doi.org/10.1023/A:1007579421768

Basuroy, S. and Chatterjee, S. 2008. "Fast and Frequent: Investigating Box Office Revenues of Motion Picture Sequels." Journal of Business Research 61(7): 798-803. http://dx.doi.org/10.1016/j.jbusres.2007.07.030

Basuroy, S., Chatterjee, S. and Ravid, S. A. 2003. "How Critical are Critical Reviews? The Box Office Effects of Film Critics, Star Power, and Budgets." Journal of Marketing 67: 103-117. http://dx.doi.org/10.1509/jmkg.67.4.103.18692

$\mathrm{Bi}, \mathrm{G}$. and Giles, D. E. 2009. "Modelling the Financial Risk Associated with U.S. Movie Box Office Earnings." Mathematics and Computers in Simulation 79(9): 2759-2766. http://dx.doi.org/10.1016/j.matcom.2008.04.014
Brookey, R. A. 2011. The International Film Business: A Market Guide Beyond Hollywood, by Angus Finney." International Journal on Media Management 13(4): 301-303. http://dx.doi.org/10.1080/14241277.2011.616107

Bruce, N. I., Foutz, N. Z. and Kolsarici, C. 2012. "Dynamic Effectiveness of Advertising and Word of Mouth in Sequential Distribution of New Products." Journal of Marketing Research 49(4): 469-486.

http://dx.doi.org/10.1509/jmr.07.0441

Brzeski, P. and Tsui, C. 2013. "China Box Office up 36 Percent to $\$ 1.79$ Billion in First Half of 2013." Retrieved 29/10/2013, from http://www.hollywoodreporter.com/news/china-boxoffice-up-36-583085

Cartier, M. and Liarte, S. 2012. "Impact of Underlying Demand and Agglomeration of Supply on Seasonality: The Case of the Hollywood Film Industry." International Jounral of Arts Management 14(2): 17-30.

Chang, B.-H. and Ki, E.-J. 2005. "Devising a Practical Model for Predicting Theatrical Movie Success Focusing on the 
Experience Good Property." Journal of Media Economics 18(4): 247-269.

http://dx.doi.org/10.1207/s15327736me1804 2

Chintagunta, P. K., Gopinath, S. and Venkataraman, S. 2010. "The Effects of Online User Reviews on Movie Box Office Performance: Accounting for Sequential Rollout and Aggregation across Local Markets." Marketing Science 29(5): 944-957. http://dx.doi.org/10.1287/mksc.1100.0572

Craig, C. S., Greene, W. H. and Douglas, S. P. 2005. "Cultural Matters: Consumer Acceptance of U.S. Films in Foreign Markets." Journal of International Marketing 13(4): 80-103. http://dx.doi.org/10.1509/jimk.2005.13.4.80

Desai, K. K. and Basuroy, S. 2005. Interactive Influence of Genre Familiarity, Star Power, and Critics' Reviews in the Cultural Goods Industry: The Case of Motion Pictures." Psychology and Marketing 22(3): 203-223. http://dx.doi.org/10.1002/mar.20055

De Vany, A. S. 2004. Hollywood Economics: How Extreme Uncertainty Shapes the Film Industry. London; New York: Routledge.

De Vany, A. S. and Walls, W. D. 2002. "Does Hollywood Make too Many R-rated Movies? Risk, Stochastic Dominance, and the Illusion of Expectation." The Journal of Business 75(3): 425451.

http://dx.doi.org/10.1086/339890

De Vany, A. S. and Walls, W. D. 2004. "Motion Picture Profit, the Stable Paretian Hypothesis, and the Curse of the Superstar. Journal of Economic Dynamics and Control" 28(6): 10351057. http://dx.doi.org/10.1016/S0165-1889(03)00065-4

Einav, L. 2007. "Seasonality in the U.S. Motion Picture Industry." The RAND Journal of Economics 38(1): 127-145. http://dx.doi.org/10.1111/j.1756-2171.2007.tb00048.x

Elberse, A. and Eliashberg, J. 2003. "Demand and Supply Dynamics for Sequentially Released Products in International Markets: The Case of Motion Pictures." Marketing Science 22(3): 329354. http://dx.doi.org/10.1287/mksc.22.3.329.17740

EntGroup. 2013a. "China Film Industry Report 2012-2013 (in brief)." Ent Report, 1-30.

EntGroup. 2013b. "China moviegoer survey report 2012-2013." Ent Report

Erdem, T. 1998. "An Empirical Analysis of Umbrella Branding." Journal of Marketing Research 35(3): 339-351. http://dx.doi.org/10.2307/3152032

Fetscherin, M. 2010. The Main Determinants of Bollywood Movie Box Office Sales. Journal of Global Marketing 23(5): 461-476. http://dx.doi.org/10.1080/08911762.2010.521117

Fu, W. W. and Lee, T. K. 2006. "Economic Determination of the Box Office Performances of Foreign Motion Pictures in the Singapore Cinema Market." International Communication Association; 2006 Annual Meeting: 1-32.

Fu, W. W. and Lee, T. K. 2008. "Economics and Cultural Influences on the Theatrical Consumption of Foreign Films in Singapore." Journal of Media Economics 21(1): 1-27. http://dx.doi.org/10.1080/08997760701806769

Greene, W. H. 2012. Econometric Analysis (7 ed.). Boston: Pearson.

Hand, C. and Judge, G. 2011. "How Stable is the Seasonal Pattern in Cinema Admissions? Evidence from the UK." Journal of Economics Letters 18: 81-85. http://dx.doi.org/10.1080/13504850903425140

Hofstede, G. H. 2013. "National Cultural Dimensions." Retrieved 04/06/2013, from http://geert-hofstede.com/nationalculture.html

Kim, E.-m. 2004. "Market Competition and Cultural Tensions between Hollywood and the Korean Film Industry." International Journal on Media Management 6(3-4): 207-216. http://dx.doi.org/10.1080/14241277.2004.9669403
Kogut, B. and Singh, H. 1988. "The Effect of National Culture on the Choice of Entry Mode." Journal of International Business Studies 19(3): 411-432. http://dx.doi.org/10.1057/palgrave.jibs.8490394

Lee, F. L. F. 2006. "Cultural Discount and Cross-culture Predictability: Examining the Box Office Performance of American Movies in HongKong." Journal of Media Economics 19(4): 259-278. http://dx.doi.org/10.1207/s15327736me1904 3

Lee, F. L. F. 2008. "Hollywood Movies in East Asia: Examining Cultural Discount and Performance Predictability at the Box Office." Asian Journal of Communication 18(2): 117-136. http://dx.doi.org/10.1080/01292980802021855

Lee, F. L. F. 2009. "Cultural Discount of Cinematic Achievement: The Academy Awards and U.S. Movies' East Asian Box Office." Journal of Cultural Economics 33(4): 239-263. http://dx.doi.org/10.1007/s10824-009-9101-7

Liebler, C. M., Jiang, W. and Chen, L. (2015). "Beauty, Binaries, and the Big Screen in China: Character Gender in Feature Films." Asian Journal of Communication 25(6): 584-599. http://dx.doi.org/10.1080/01292986.2015.1019525

Litman, B. R. 1998. The Motion Picture Mega-industry: Boston: Allyn and Bacon.

Liu Y. 2006. "Word of Mouth for Movies: Its Dynamics and Impact on Box Office Revenue." Journal of Marketing 70(3): 74-89. http://dx.doi.org/10.1509/jmkg.70.3.74

McFadyen, S., Hoskins, C. and Finn, A. 2004. "The Effect of Program Type on the Cultural Discount in the Price of Exported U.S. Television Programs." Paper presented at the Applied Econometrics Association International Conference on Econometrics of Cultural Goods, Padua, Italy.

McKenzie, J. 2012. "The Economics of Movies: A Literature Survey." Journal of Economic Surveys 26(1): 42-70. http://dx.doi.org/10.1111/j.1467-6419.2010.00626.x

Moon, S., Bergey, P. K. and lacobucci, D. 2010. "Dynamic Effects among Movie Ratings, Movie Revenues, and Viewer Satisfaction." American Marketing Association 74: 108-121.

Nation Bureau of Statistics of China. 2012. China Statistical Yearbook. Retrieved 01/06/2013, from http://www.stats.gov.cn/tjsj/ndsj/2012/indexch.htm

Palia, D., Ravid, S. A. and Reisel, N. 2008. "Choosing to Cofinance: Analysis of Project-specific Alliances in the Movie Industry." Review of Financial Studies 21(2): 483-511. http://dx.doi.org/10.1093/rfs/hhm064

Poupard, L. V. 2008. "How the Current Financial Crisis will Hurt the Movie Industry for a Long Time?" Retrieved 29/10/2013, from http://voices.yahoo.com/how-current-financial-crisis-will-hurtmovie-2216030.html

Ravid, S. A. 1999. "Information, Blockbusters, and Stars: A Study of the Film Industry." The Journal of Business 72(4): 463-492. http://dx.doi.org/10.1086/209624

Redondo, I. and Holbrook, M. B. 2010. "Modeling the Appeal of Movie Features to Demographic Segments of Theatrical Demand." Journal of Cultural Economics 34(4): 299-315. http://dx.doi.org/10.1007/s10824-010-9127-x

Reinstein, D. A. and Snyder, C. M. 2005. "The Influence of Expert Reviews on Consumer Demand for Experience Goods: A Case Study of Movie Critics." Journal of Industrial Economics 53(1): 27-51. http://dx.doi.org/10.1111/j.0022-1821.2005.00244.x

Schiller, H. I. 1992. Mass Communications and American Empire. Boulder: Westview Press.

Su, Y. 2010. "Chinese Box Office Grow 43\% to Hit $\$ 908 m$ in 2009." Retrieved 16/01/2013, from http://www.chinadaily.com.cn/ bizchina/2010-01/09/content_9293353.htm

Tomlinson, J. 1991. Cultural Imperialism: A Critical Introduction. London: Pinter Publishers. 
Walls, W. D. 2005a. "Modeling Movie Success When 'Nobody Knows Anything': Conditional Stable-distribution Analysis of Film Returns." Journal of Cultural Economics 29(3): 177-190. http://dx.doi.org/10.1007/s10824-005-1156-5

Walls, W. D. 2005b. "Modelling Heavy Tails and Skewness in Film Returns." Applied Financial Economics 15(17): 1181-1188. http://dx.doi.org/10.1080/0960310050391040

Walls, W. D. and McKenzie, J. 2012. "The Changing Role of Hollywood in the Global Movie Market." Journal of Media Economics 25(4): 198-219.

http://dx.doi.org/10.1080/08997764.2012.729544
Yeh, E. Y.-y. 2009. "Pitfalls of Cross-cultural Analysis: Chinese Wenyi Film and Melodrama." Asian Journal of Communication 19(4): 438-452. http://dx.doi.org/10.1080/01292980903293379

Zhou, X. 2001. "From behind the Wall' The Representation of Gender and Sexuality in Modern Chinese Film." Asian Journal of Communication 11(2): 1-17. http://dx.doi.org/10.1080/01292980109364801

Received on 08-03-2016

Accepted on 20-04-2016

Published on 03-06-2016

DOI: http://dx.doi.org/10.6000/1929-7092.2016.05.17

(C) 2016 Feng and Sharma; Licensee Lifescience Global.

This is an open access article licensed under the terms of the Creative Commons Attribution Non-Commercial License (http://creativecommons.org/licenses/by-nc/3.0/) which permits unrestricted, non-commercial use, distribution and reproduction in any medium, provided the work is properly cited. 